
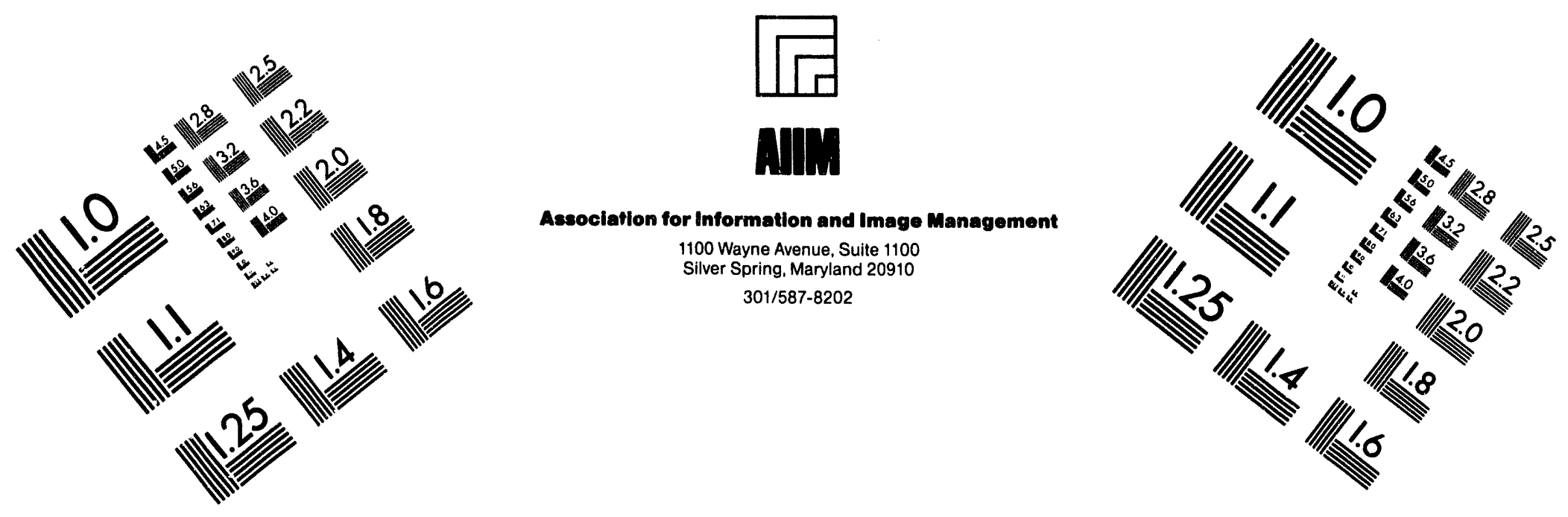

\title{
Centimeter
}

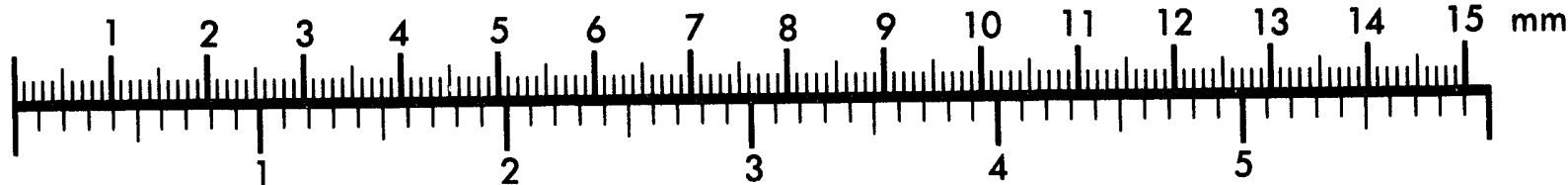
Inches
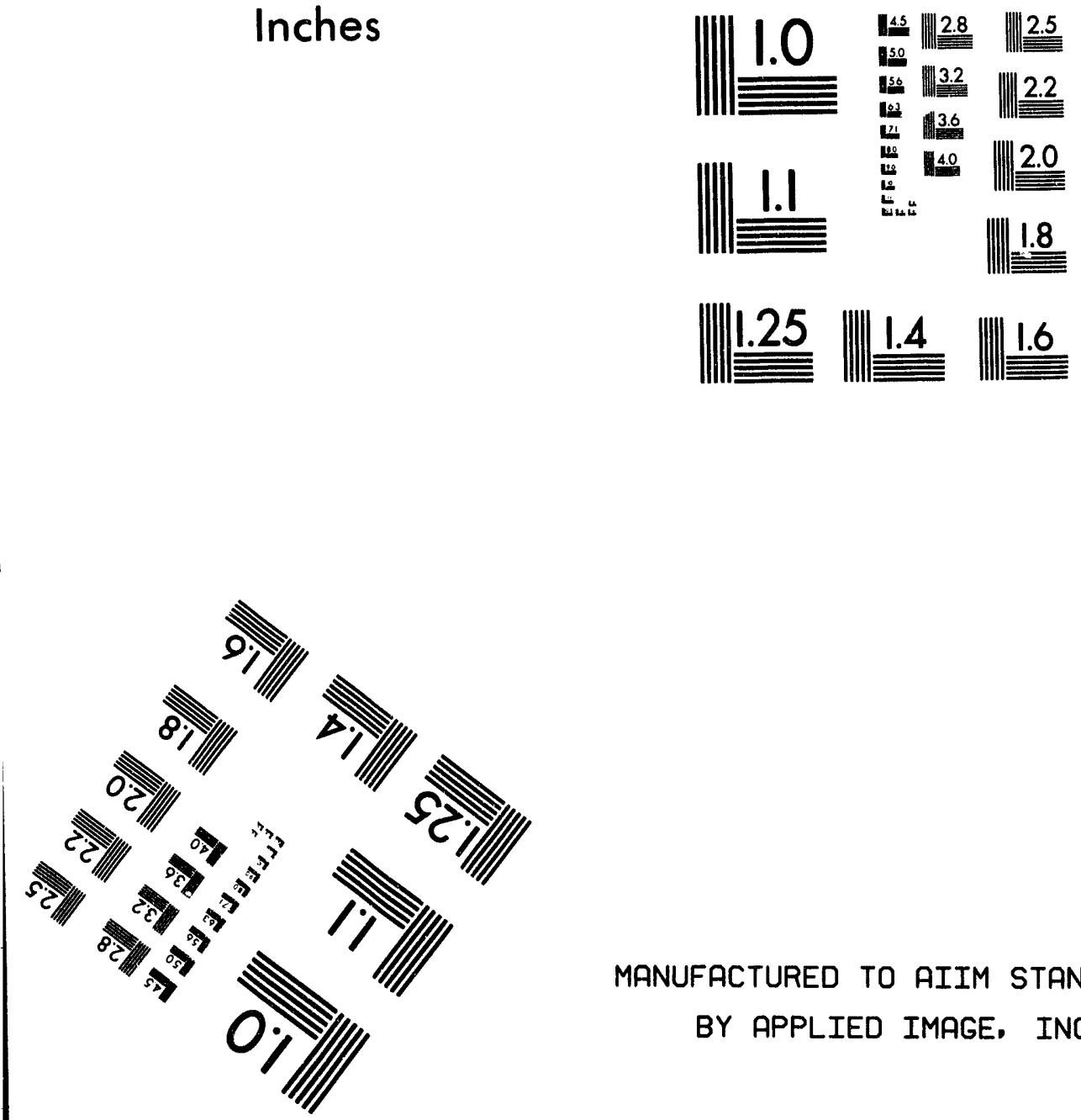

MANUFACTURED TO AIIM STANDARDS

BY APPLIED IMAGE, INC.

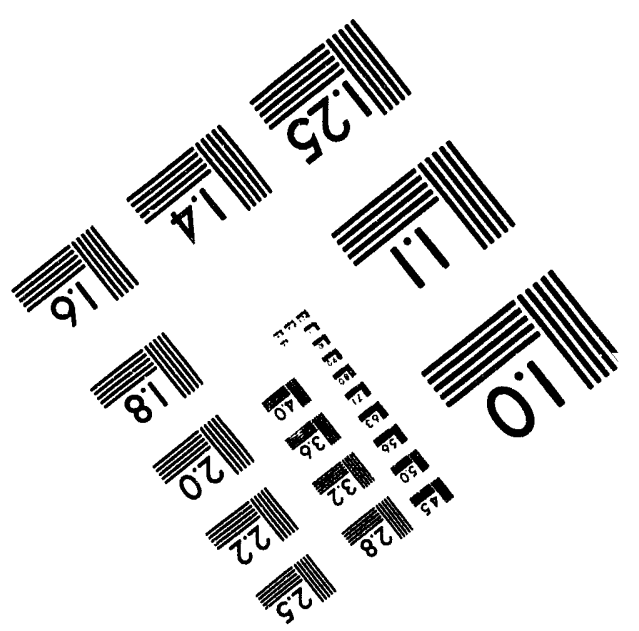



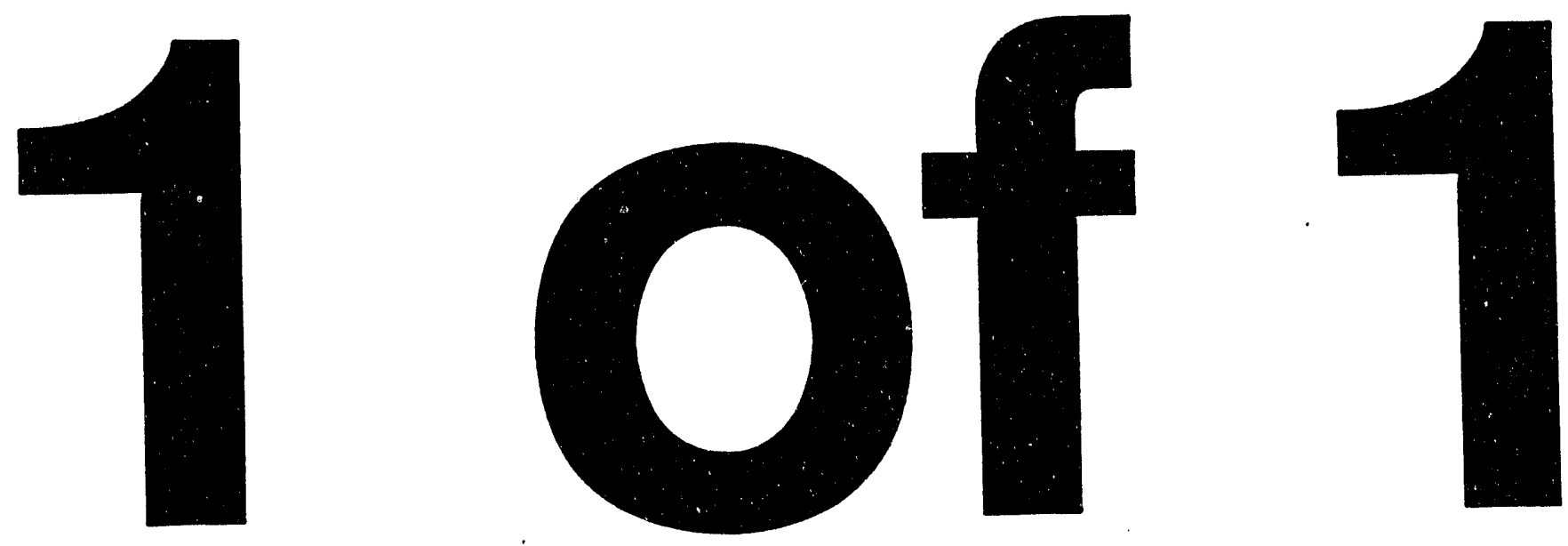


\section{IMPLICATIONS OF ACCESS HOLE SIZE ON TANK WASTE RETRIEVAL SYSTEM DESIGN AND COST}

S. M. Babcock, D. S. Kwon, and B. L. Burks

Robotics \& Process Systems

Oak Ridge National Laboratory

P.O. Box 2008

Oak Ridge, Tennessee 37830-6304

R. S. Stoughton and M. S. Evans

Automation and Measurement Sciences

Pacific Northwest Laboratory

Battelle Boulevard

P.O. Box 999

Richland, Washington 99352

Date Published-May 1994

Notice: This document contains information of a preliminary nature. It is subject to revision or correction and therefore does not represent a final report.

Prepared by the

OAK RIDGE NATIONAL LABORATORY

Oak Ridge, Tennessee 37831

managed by

MARTIN MARIETTA ENERGY SYSTEMS, INC.

for the

U.S. DEPARTMENT OF ENERGY

under contract DE-AC05-84OR21400 
ABSTRACT...................................................................................................ii

1. INTRODUCTION ..................................................................................................

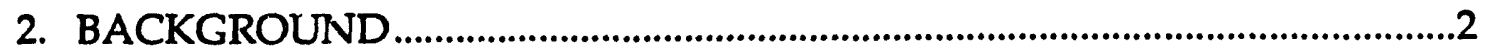

3. ORNL AND PNL PARAMETRIC STUDIES ON MANIPULATOR

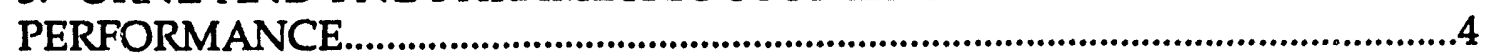

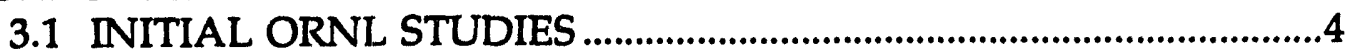

3.2 EXPANDED ORNL STUDIES.............................................................

3.2.1 Assumptions and Approach ....................................................

3.2.2 Case Studies..................................................................................6

3.2.3 Conclusions of the Study ..........................................................

3.3 EXTENSIONS TO ORNL FY 1992 STUDIES ..........................................8

3.3.1 Modifications to Assumptions .................................................

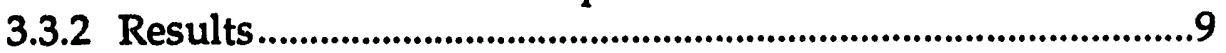

3.3.3 Conclusions of the Extended Study ..........................................10

3.4 PNL STUDIES.................................................................................................11

3.4.1 Assumptions and Approach ......................................................11

3.4.2 Results.................................................................................12

3.4.3 Conclusions of the PNL Study..............................................13

3.5 COMPARISON OF ORNL AND PNL STUDIES...................................14

3.6 CONCLUSIONS FROM THE MANIPULATOR

PERFORMANCE STUDIES .............................................................................15

4. PRACTICAL STRUCTURAL LIMITATIONS....................................................16

5. RISER INSTALLATION STATE-OF-THE-ART LIMITATIONS....................17

6. RADIATION SAFETY IMPLICATIONS..............................................................18

7. OVERALL SYSTEM COST IMPLICATIONS.....................................................19

8. CONCLUSIONS ................................................................................................2

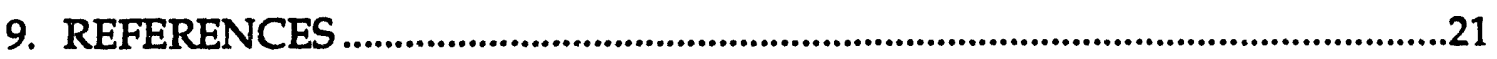




\begin{abstract}
The DOE Environmental Restoration and Waste Management Robotics Technology Development Program has been investigating the application of robotics technology to the retrieval of waste from single-shell storage tanks for several years. The use of a large, "long-reach" manipulator to position and orient a variety of tools and other equipment has been recommended.

The objective of this study is to determine the appropriate access hole size for the tank waste retrieval system installation. Previous reports on the impact of access hole size on manipulator performance are summarized. In addition, the practical limitation for access hole size based on structural limitations of the waste storage tanks, the state-of-the-art size limitations for the installation of new risers, the radiation safety implications of various access hole sizes, and overall system cost implications are considered. Basic conclusions include: (1) overall cost of remediation will be dominated by the costs of the balance of plant and time required to perform the task rather than the cost of manipulator hardware or the cost of installing a riser, (2) the most desirable solution from a manipulator controls point of view is to make the manipulator as stiff as possible and have as high as possible a natural frequency, which implies a large access hole diameter, (3) beyond some diameter; simple, uniform cross-section elements become less advantageous from a weight standpoint and alternative structures should be considered, and (4) additional shielding and contamination control measures would be required for larger holes. Parametric studies summarized in this report considered 3,790,000 l (1,000,000 gal) tanks, while initial applications are likely to be for $2,840,0001(750,000 \mathrm{gal})$ tanks. Therefore, the calculations should be somewhat conservative, recognizing the limitations of the specific conditions considered.
\end{abstract}




\section{INTRODUCTION}

The objective of this study is to determine the appropriate access hole size for tank waste retrieval system installation. At least five separate topics are associated with this study: (1) the impact of access hole size on manipulator performance, (2) the practical limitation for access hole size based on structural limitations of the waste storage tanks, (3) the state-of-the-art size limitations for the installation of new risers, (4) the radiation safety implications of various access hole sizes, and (5) overall system cost implications. 


\section{BACKGROUND}

For several years, the U.S. Department of Energy, Office of Technology Development, Environmental Restoration and Waste Management Robotics Technology Development Program (RTDP) has been investigating the application of robotics technology to the retrieval of waste from single-shell storage tanks. These investigations have resulted in the recommendation that a remediation system based on the use of a large, "long-reach" manipulator be employed to position and orient a variety of tools and other equipment that will be necessary to dislodge and retrieve waste and in-tank hardware. Preliminary demonstrations of this technology have been performed by using a large manipulator developed for another nuclear application and not closely representative of a configuration that would be suitable for actual use in waste storage tink remediation. A current program objective is to procure a representative manipulator or parts of such a manipulator for installation in a test bed to allow the development of needed telerobotic capabilities. In parallel with this effort, a first-generation manipulator system suitable for near-term remediation of some subset of the approximately 150 single-shell tanks at the Hanford site will be procured. In support of these efforts, the RTDP areas of cross-cutting and advanced technology and tank waste retrieval have maintained activities to define the requirements and develop specifications for the test bed manipulator and to perform studies in support of the procurement of a first-generation retrieval system.

Although the concept of using a long-reach manipulator for waste storage tank remediation is not new, questions regarding the practicality and commercial availability of such a manipulator have led to conceptual design studies and applied research activities supported by the cross-cutting and advanced technology and tank waste retrieval areas of the RTDP. These studies have focused primarily on kinematic design issues and control algorithm development for robots with structural flexibility; however, hole size implications have also been addressed. Studies conducted have included investigations at Pacific Northwest Laboratory (PNL) and Oak Ridge National Laboratory (ORNL) concerning the anticipated dynamic characteristics of a long-reach manipulator that could be deployed through a constrained opening in a tank (i.e., tank riser). Structural limitations of the Hanford site single-shell tanks have been investigated from two viewpoints: (1) the maximum remediation system load that could be supported within tank farm boundaries and, (2) the maximum access hole size that could be made in the tanks without impacting tank structural integrity. The question of state-ofthe-art limitations in the size of a tank penetration has also been investigated. Assuming that the above issues are not limiting, radiation safety implications have been investigated. A final issue, and possibly the bottom-line issue, is cost. This issue has been addressed only superficially because all of the above 
issues have interrelated cost implications. The results to date of these studies are summarized in the following sections. 


\section{ORNL AND PNL PARAMETRIC STUDIES ON MANIPULATOR PERFORMANCE}

\subsection{INITIAL ORNL STUDIES}

Initial parametric studies were made by the RTDP in 1991 and reported in Long-Reach Manipulation for Waste Storage Tank Remediation-FY 1991 Report [Jansen 1992]. The simple case of a cantilevered beam (clamp-free boundary conditions) with a circular cross section, representing only the horizontal portion of the long-reach manipulator (not including a deployment mast), was considered. A beam with a length of $9.1 \mathrm{~m}(30 \mathrm{ft})$ and diameters of $0.51 \mathrm{~m}(20 \mathrm{in}$.) and $0.76 \mathrm{~m}$ (30 in.) were considered with payloads of $454 \mathrm{~kg}(1000 \mathrm{lb})$ and $907 \mathrm{~kg}(2000 \mathrm{lb})$. For a wall thickness of $0.0254 \mathrm{~m}$ (1.0 in.), static deflections due to the weight of the beam itself and the assumed loads ranged between $0.0061 \mathrm{~m}(0.24 \mathrm{in}$.) and $0.0206 \mathrm{~m}(0.81 \mathrm{in}$.) for steel. Natural frequencies for the first transverse vibration wave mode ranged between 6.05 and $9.07 \mathrm{~Hz}$ for a steel beam. Material properties of aluminum and titanium as well as steel had little effect on the results. Composite materials were briefly considered because of the potential for damping improvement, but the potential high cost removed them from consideration. It was noted that the natural frequency can be expressed in a form which shows that it is basically independent of material for steel, aluminum, and titanium because of similarities in the ratios of structural parameters (modulus of elasticity/density). Also noted was that tapering of the beam could improve the natural frequency by roughly a factor of 2 [Blevens 1979].

Although the wall thickness used in this study was not optimal, the objective of the study was to obtain a rough estimate of the frequency of the first mode of vibration. This estimation is important because servo bandwidths are generally limited to $<67 \%$ of that frequency. In the report [Jansen 1992], the possible advantage of using multiple access holes to reduce the length of a retrieval manipulator was considered. The use of four ports would reduce the required horizontal reach by only $18 \%$, which is insignificant compared to the associated increase in cost and complexity to reposition the manipulator system multiple times.

\subsection{EXPANDED ORNL STUDIES}

More extensive paranietric studies were conducted in FY 1992 and reported in Key Design Requirements for Long-Reach Manipulators [Kwon 1993a] and Parametric Design Studies of Long-Reach Manipulators [Kwon 1993b]. 


\subsubsection{Assumptions and Approach}

Payload, strength, allowable static deflection, and access hole diameter were identified as design constraints in addition to the required volumetric coverage. The problem was formulated as an optimization problem to minimize weight subject to constraints on access port diameter, maximum static deflection at the tip for a given load, and maximum bending stress. Payload was considered via its impact on bending stress and static deflection. Design variables were the link diameters and thicknesses. The potential for local buckling and stress concentration were allowed to limit the minimum wall thickness. "Buckling occurs when a member or a structure converts membrane strain energy into strain energy of bending with no change in externally applied load" [Cook, 1989]. A minimum wall thickness of $0.00318 \mathrm{~m}(0.125 \mathrm{in}$.) was assumed.

Two fundamentally different mechanical corfigurations were considered, one that must be sequentially deployed and one that incorporates a manipulator which unfolds out of the mast after deployment of the mast. The short-reach, dexterous manipulator typical of the program's design concepts was considered only as part of the long-reach manipulator's load. Access hole diameters between $0.61 \mathrm{~m}$ (24 in.) and $1.52 \mathrm{~m}$ (60 in.) were considered. Estimates of actuator weights were included. Only deflections due to bending were considered. Simple hexagonal cross-section masts and square cross section manipulator links were assumed, because of the likelihood that commercial vendors would elect not to fabricate masts and manipulator links with circular cross-sections. For the sequential entry concept, a set of minimum link characteristic diameters for the mast and manipulator links were assumed. For the folded entry concept, similar constraints on the manipulator links were assumed, but the minimum mast characteristic diameter was constrained to house the folded manipulator. In both cases, the maximum mast diameter was assumed to be $80 \%$ of the access hole diameter to allow for factors such as misalignment and sealing. A structural strength design criterion which included a factor of safety of 2.5 and 260,000 cycles was applied to the maximum stress point. (It was assumed that 260,000 cycles of maximum load could be applied during six months of operation.) Actuator and servo stiffness were not considered in this portion of the report but were addressed separately.

A parametric analysis procedure was developed and imp.emented by using the Mathematica software tool. Four parameters were chosen for study: static deflection criteria, payload, access hole size, and tank diameter. These parameters were investigated in two groups, with nominal values used for the fixed-pair parameters. An iterative procedure allowed successive optimization of each link size to minimize weight while satisfying the strength design criteria, static deflection design criteria, and other constraint 
conditions. Only a discrete set of wall thicknesses was allowed, increments of $1.6 \mathrm{~mm}(1 / 16 \mathrm{in}$.$) , and the minimum wall thickness allowed was 3.2 \mathrm{~mm}$ (1/8 in.). After link dimensions were calculated, actuator weight was estimated. Reaction forces and moment distributions were calculated, and the iterative procedure was applied successively to the next link. After all links were addressed, the total system weight, static deflection, and fundamental natural frequency (approximately proportional to $1 /$ [static deflection] ${ }^{(1 / 2)}$ ) were calculated. The procedure was then repeated for other values of the parameters being varied.

\subsubsection{Case Studies}

Four case studies were made: (1) varying the static deflection requirement with different payloads for a sequential entry manipulator, (2) varying the access hole diameter with different tank sizes for a sequential entry manipulator, (3) varying the static deflection requirement with different payloads for a folded entry manipulator, and (4) varying the access hole diameter with different tank sizes for a folded entry manipulator.

In the first and third case studies, the static deflection requirement was varied between 0.10 and $0.30 \mathrm{~m}$ ( 4 and $12 \mathrm{in}$.), and payloads of 227, 454, and $681 \mathrm{~kg}$ $(500,1000$, and $1500 \mathrm{lb})$ were considered with the access hole size restricted to $1.1 \mathrm{~m}$ (42 in.) and the tank radius restricted to $11.6 \mathrm{~m}$ (38 ft). The resulting data were presented in the form of several plots, including (1) weight vs static deflection criteria with maximum payload for various payloads, (2) natural frequency with maximum payload vs static deflection design criteria with maximum payload, (3) natural frequency with no payload vs static deflection design criteria with maximum payload for various payloads, (4) mast (or column) size vs static deflection design criteria with maximum payload for various payloads, and (5) no-load static deflection vs static deflection design criteria with maximum payload for various payloads.

In the second and fourth case studies, the tank radii of 7.3, 9.4, and $11.6 \mathrm{~m}$ $(24,31$, and $38 \mathrm{ft}$ ) and access hole diameters varying from 0.64 to $1.40 \mathrm{~m}$ ( 25 to $55 \mathrm{in}$.) were considered with the payload fixed to be $454 \mathrm{~kg}(1000 \mathrm{lb})$ and the static deflection at maximum payload fixed to be $0.15 \mathrm{~m}$ (6 in.). The resulting data were presented in the form of several plots, including (1) weight vs access hole diameter for various tank radii, (2) natural frequency with maximum payload vs access hole diameter for various tank radii, (3) natural frequency with no payload vs access hole diameter for various tank radii, (4) mast (or column) size vs access hole diameter for various tank radii, (5) static deflection with maximum payload vs access hole diameter for various tank radii, and (6) no-load static deflection vs access hole diameter for various tank radii. 
For the first case, the sequential entry manipulator with a $1.1-\mathrm{m}$ (42-in.) access hole diameter and a $11.6-\mathrm{m}-(38-\mathrm{ft}-)$ radius tank, the total weight increased dramatically for static deflection criteria $<0.10 \mathrm{~m}$ (4 in.). For the $454-$ and $681-\mathrm{kg}$ (1000- and 1500-lb) load conditions, the column diameter reached a maximum with the minimum wall thickness for a $0.18-\mathrm{m}$ (7-in.) static deflection design criteria. The wall thickness increased for static deflection design criteria $<0.18 \mathrm{~m}$ (7 in.).

For the second case, the sequential entry manipulator with a 454-kg (1000-1b) load and a static deflection design criteria of $0.15 \mathrm{~m}$ (6 in.), the total weight increased dramatically for access hole diameters less than $\sim 0.89 \mathrm{~m}$ (35 in.). For the 11.6-m- (38-ft-) radius tank, no larger than a $1.17-\mathrm{m}$ (46-in.) access hole was necessary, because the maximum column outer dimension with the minimum wall thickness satisfied the requirements for the conditions considered. However, for a 1.17-m (46-in.) access hole diameter, a more restrictive static deflection requirement would result in increased wall thickness. Therefore, if the static deflection requirement is restricted to $<0.15 \mathrm{~m}$ ( 6 in.), the availability of a larger access hole could reduce the needed wall thickness and the total manipulator weight.

For the third case, the folded entry manipulator with a $1.1-\mathrm{m}$ (42-in.) access hole diameter and a $11.6-\mathrm{m}-(38-\mathrm{ft}-)$ radius tank, the total weight increased dramatically for static deflection criterion $<0.15 \mathrm{~m}(6 \mathrm{in.}) . \quad A<0.11-\mathrm{m}(4.5$-in.) static deflection design criterion made the column diameter exceed the maximum ( $80 \%$ of the access hole diameter) even with the maximum wall thickness, which was limited by the foldable structure.

For the fourth case, the folded entry manipulator with a 454-kg (1000-lb) payload and a static deflection design criterion of $0.15 \mathrm{~m}$ (6 in.), the total weight increased dramatically for access hole diameters less than $\sim 1.14 \mathrm{~m}$ (45 in.).

Although hole sizes $>1.52 \mathrm{~m}$ (60 in.) were not considered in the study, increasing the hole size from $1.07 \mathrm{~m}$ (42 in.) to $1.52 \mathrm{~m}$ (60 in.) resulted in lighter manipulators for the same static deflection because of a decrease in wall thickness. This result implies that for more restrictive static deflection criteria than considered in the study, further increasing the access hole diameter would result in a lighter manipulator.

\subsubsection{Conclusions of the Study}

Design of a long-reach manipulator and associated mast will involve conflicting goals such as minimum weight, minimum tower height, maximum structural natural frequency, and maximum actuator bandwidth. Quantitative estimates for weight, static deflection, and natural frequencies 
were obtained for the assumptions and approach taken. Note that the study was limited to uniform cross-section mast and manipulator link sections and that actuator and servo stiffness were considered separately.

In this study, a range of static deflection requirements, specified in terms of static deflection per unit length, was considered. It was concluded that for a sequential entry manifulator for a $11.6-\mathrm{m}-(38-\mathrm{ft}$-) diameter tank with $1.07-\mathrm{m}$ (42-in.) access hole diameter, static deflections in the range of 0.10 to $0.15 \mathrm{~m}$ (4 to 6 in.) would be reasonable. For the folded entry manipulator, static deflections in the range of 0.15 to $0.20 \mathrm{~m}$ ( 6 to $8 \mathrm{in}$.) would be reasonable. For static deflection requirements $>0.25 \mathrm{~m}$ (10 in.), the strength criterion dominated. The deflection of the mast or column appears to be a significant contributor to the effective overall system static deflection.

The manipulator natural frequency was not dramatically affected by the application of more severe design constraints. Fundamental natural frequencies in the range of 1 to $2 \mathrm{~Hz}$ are expected (ignoring actuator and servo stiffness and considering bending only).

Practical lower limits on the access hole size were obtained because of the approach taken in this study. As the access hole size is reduced, the wall thickness is increased to meet the design criteria, resulting in heavier and heavier manipulator designs. As the access hole size is increased, the wall thickness is reduced to the minimum practical. Note again that only uniform cross-section mast sections and links were considered; the use of truss structures would be advantageous when the wall thicknesses of a uniform cross-section design are reduced to a buckling limit. Common approaches to obtain a "truss-like" or nonuniform cross-section structure include cutouts and reduced wall thickness areas.

From comparison of a sequential entry manipulator with a folded entry manipulator, it was concluded that the folded entry manipulator would be heavier for the same static deflection or would have a greater static deflection and lower fundamental natural frequency for the same weight, all other design criteria being the same. In general, a folded entry manipulator would require a larger access hole. However, a folded entry manipulator would have deployment, failure recovery, and tower height advantages.

\subsection{EXTENSIONS TO ORNL FY 1992 STUDIES}

\subsubsection{Modifications to Assumptions}

In FY 1993, the results of the earlier study were extended to address larger access hole diameters, more closely approximate the expected length of the 
long-reach manipulator, and more closely approximate the expected loading due to the short-reach, dexterous manipulator and end effectors [Kwon 1993c]. As in the previous study, the problem was formulated as an optimization problem to minimize weight subject to constraints on access port diameter, maximum static deflection at the tip for a given load, and maximum bending stress. Payload was considered via its impact on bending stress and static deflection, design variables were the link diameters and thicknesses, and buckling constraints were considered by specifying a minimum wall thickness of $1.6 \mathrm{~mm}(1 / 8 \mathrm{in}$.$) .$

The range of access hole diameters considered was increased from 0.89 to $1.78 \mathrm{~m}$ (35 to $70 \mathrm{in}$.), the length of the long-reach manipulator was reduced

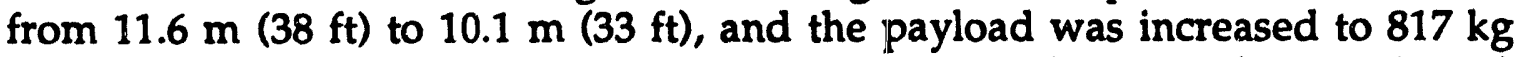
(1800 lb). Static deflection criteria of $0.0254,0.0762$, and $0.152 \mathrm{~m}(1,3$, and $6 \mathrm{in}$.) were considered. The maximum column size was restricted as in the previous study to $80 \%$ of the access hole diameter. This study was restricted to considering a sequential entry manipulator for various access hole sizes and static deflection design criteria with the manipulator length and payload fixed. Note that, as in the previous study, the mast was assumed to be a single, constant cross section element and the long-reach manipulator was assumed to have three sections, the outer two having the same cross-section.

\subsubsection{Results}

The resulting data were presented in the form of plots including (1) weight vs access hole diameter for various static deflection design criteria, (2) natural frequency with maximum payload vs access hole diameter for various static deflection design criteria, (3) natural frequency with no payload vs access hole diameter for various static deflection design criteria, (4) mast (or column) size vs access hole diameter for various static deflection design criteria, (5) mast (or column) wall thickness vs access hole diameter for various static deflection design criteria, (6) size of the first section of the long-reach manipulator vs access hole diameter for various static deflection design criteria, (7) wall thickness of the first section of the long-reach manipulator vs access hole diameter for various static deflection design criteria, (8) size of the second section of the long-reach manipulator vs access hole diameter for various static deflection design criteria, (9) wall thickness of the second section of the long-reach manipulator vs access hole diameter for various static deflection design criteria, (10) static deflection with maximum payload vs access hole diameter for various static deflection design criteria, and (11) no-load static deflection vs access hole diameter for various static deflection design criteria.

For a static deflection design criterion of $0.0254 \mathrm{~m} \mathrm{(1} \mathrm{in.),} \mathrm{a} \mathrm{total} \mathrm{weight} \mathrm{of}$ $\sim 53,300 \mathrm{~N}(12,000 \mathrm{lbf})$ was obtained for an access hole diameter of $1.52 \mathrm{~m}$ 
(60 in.), and the total weight increased rapidly for smaller access hole diameters. For a static deflection criterion of $0.15 \mathrm{~m}(6 \mathrm{in}$.), there was no significant difference in weight in the range of 1.07 to $1.78 \mathrm{~m}$ (42 to $70 \mathrm{in}$.). For a static deflection criterion of $0.0762 \mathrm{~m}$ ( 3 in.), an increase in access hole size from 1.07 to $1.40 \mathrm{~m}$ (42 to $55 \mathrm{in}$.) resulted in an $\sim 40 \%$ reduction in weight. Additional reduction in weight was obtained for a 1.79-m (70-in.) access hole diameter.

Reasonable column thicknesses of $<0.0127 \mathrm{~m}$ ( $0.5 \mathrm{in}$.) were obtained for static deflection criteria of 0.0762 and $0.152 \mathrm{~m}$ ( 3 and 6 in.), but for a static deflection criterion of $0.0254 \mathrm{~m}$ ( 1 in.), column thickness increased rapidly beyond $0.0127 \mathrm{~m}(0.5 \mathrm{in}$.) for access hole diameters < 1.34 or $1.52 \mathrm{~m}$ (55 or $60 \mathrm{in.}$.). Similar results were obtained for the first and second sections of the long-reach manipulator.

The sizes (side lengths of a square cross section) of the first section of the longreach manipulator were approximately $0.83,0.71$, and $0.58 \mathrm{~m}$ (33, 28, and 23 in.) for a 1.78-m (70-in.) access hole diameter for static deflection criteria of $0.0254,0.0762$, and $0.152 \mathrm{~m}(1,3$, and $6 \mathrm{in}$.). The sizes of the other section (second and third links) of the long-reach manipulator were similar to those of the first section.

Fundamental natural frequencies of the column and manipulator with the maximum payload were $3, \sim 1.75$, and 1 to $1.4 \mathrm{~Hz}$ for the various static deflection criteria. With no payload, the fundamental natural frequencies ranged from 2 to $>5 \mathrm{~Hz}$, with that of the $0.152-\mathrm{m}(6-\mathrm{in}$.) criterion $\sim 3 \mathrm{~Hz}$ for a 1.83-m (72-in.) access hole size. Note that in practice, the no-load case will not occur, because of the presence of at least the short-reach, dexterous manipulator.

\subsubsection{Conclusions of the Extended Study}

As expected, the total weight of the column and manipulator are reduced by increasing the access hole size; however, the reduction in weight is more significant for tighter static deflection design criteria. Also, weight is significantly increased by reducing the static deflection criterion from 0.0762 to $0.0254 \mathrm{~m}$ ( 3 to $1 \mathrm{in}$.). The diameters of the links of the long-reach manipulator that resulted from this optimization approach were generally in the range of 0.51 to $0.76 \mathrm{~m}$ ( 20 to $30 \mathrm{in}$.), with wall thicknesses $<0.0076 \mathrm{~m}$ ( $0.3 \mathrm{in}$.) for all but the tightest static deflection design criterion and access hole diameters less than $\sim 1.40 \mathrm{~m}$ (55 in.). Fundamental natural frequencies with the maximum payload that were implied by the approximate relation to static deflection were obtainable throughout the range of parameters considered at the expense of weight. The differences in the results from those of the previous 
study were consistent with the changes in the long-reach manipulator length, payload, and static deflection criteria considered.

In this study, which considered only uniform cross-section elements, increasing the access hole size resulted in reduced manipulator weight until the minimum wall thickness required to satisfy the assumed buckling constraint was obtained. For a $0.0254-\mathrm{m}$ (1-in.) static deflection requirement, this limit was reached with a $1.65-\mathrm{m}$ (65-in.) diameter access hole size. For a $0.0762-m(3-i n$.) static deflection requirement, the limit was reached with a 1.40-m- (55-in.-) diameter access hole size. For a 0.178-m (7-in.) static deflection requirement, the limit was reached with a 1.14-m- (45-in.-) diameter access hole size. However, if a "truss-like" structure (which may not have the buckling problem due to a thin wall) can be considered, larger hole diameters may contribute effectively to the reduction of the manipulator weight and the increase of the structural stiffness.

\subsection{PNL STUDIES}

\subsubsection{Assumptions and Approach}

In the PNL study [Stoughton 1994], a structure more complex than that in the ORNL studies was considered. The mast was assumed to consist of three sections (representative of a set of telescoping tubes) and the long-reach manipulator was assumed to consist of three sections of possibly different diameters (more representative of a three-link manipulator). A fourth beam was added to represent the short-reach, dexterous manipulator. Finite element analysis was used as input to an optimization routine that varied the diameters and thicknesses of the arm sections to maximize the lowest system natural frequency. Maximizing the lowest natural frequency generally maximizes the ratio of stiffness to weight.

The problem was formulated to maximize the lowest natural frequency, subject to constraints on the maximum stress and buckling constraints on all links including the mast. The buckling constraint employed maintained the ratio of diameter to wall thickness at $\leq 50$. (Note that this diameter-to-wall thickness ratio is significantly less than that used in the ORNL studies discussed above.) The link diameters and thicknesses were used as design variables.

The finite-element model consisted primarily of 3-dimensional beam elements, with mass elements added to model the actuators, the short-reach manipulator, and the end-effector masses. The mast was assumed to telescope in three circular cross-section parts $6.10,5.18$, and $3.96 \mathrm{~m}$ $(20,17$, and $13 \mathrm{ft})$ in length. The diameter of the second mast section was set 
to be 0.96 times the diameter of the initial section, and the diameter of the third mast section was set to be 0.92 times that of the initial section. A bearing support was assumed $1.52 \mathrm{~m}(5 \mathrm{ft})$ from the top of the $15.2-\mathrm{m}(50-\mathrm{ft})$ mast. A point mass of $45.4 \mathrm{~kg}(100 \mathrm{lb})$ was added at the top of the mast to model the moving portion of the mast rotation actuator. A point mass of $90.7 \mathrm{~kg}(200 \mathrm{lb})$ was added at the bottom of the mast.

The arm extending from the bottom of the mast was modeled as three beams, each of constant circular cross section and $3.35 \mathrm{~m}(11 \mathrm{ft})$ in length. Point masses of 54.4 and $36.3 \mathrm{~kg}$ (120 and $80 \mathrm{lb}$ ) were placed between the first and second arm sections respectively to model the actuators.

The short-reach manipulator was modeled as a constant circular cross-section beam $1.52 \mathrm{~m}(5 \mathrm{ft})$ in length extending horizontally from the end of the third section of the long-reach manipulator (equivalent to a $3.05 \mathrm{~m}$ (10 ft) arm at $\left.60^{\circ}\right)$. The total mass of the short-reach manipulator was assumed equal to that of the end effector. Half of this mass was associated with a point mass located at the end of the third section of the long-reach manipulator. The diameter of the short-reach manipulator was determined so that the mass of the beam modeling the short-reach manipulator would be half that of the end-effector. The thickness of the beam modeling the short-reach manipulator was assumed to be one fourth of the diameter.

The beam element size was set to $0.152 \mathrm{~m}$ (6 in.), resulting in 176 3-D elements. The diameters and thicknesses of the three sections of the longreach manipulator were used as design variables for optimization. The diameters of the arm sections were required to be less than the mast diameter and that they step down sequentially.

\subsubsection{Results}

The optimization run was made for nine different mast diameters [8.53, 9.75, 11.0, 12.2, 13.4, 14.6, 15.8, 17.1, and $19.5 \mathrm{~m}(28,32,36,40,44,48,52,56$, and 64 in.)] and for seven different end effector loads [113, 181, 272, 363, 454, 567, and $681 \mathrm{~kg}(250,400,600,800,1000,1250$, and $1500 \mathrm{lb})]$ for a total of 63 runs. In the ORNL study above, the $1.78-\mathrm{m}$ (70-in.) access hole diameter is equivalent to a $1.42-\mathrm{m}$ (56-in.) mast size, given the $80 \%$ assumption.

The data were presented in a series of plots: (1) fundamental frequency vs mast diameter for different end-effector loads, (2) tip static deflection vs mast diameter for different end-effector loads, (3) total weight vs mast diameter for different end-effector loads, and (4) maximum stress vs mast diameter for different end-effector loads. 
The data indicated an approximately linear relationship between the mast diameter and the lowest natural frequency. A natural frequency of $3 \mathrm{~Hz}$ was achieved with a mast diameter of $1.27 \mathrm{~m}$ (50 in.) and a payload of $454 \mathrm{~kg}$ $(1000 \mathrm{lb})$. This result likely corresponds to a little over $2 \mathrm{~Hz}$ when joint compliance is considered.

With mast diameters greater than $\sim 1.07 \mathrm{~m}$ (42 in.), the static deflection of the tip fell below $0.058 \mathrm{~m}(2 \mathrm{in}$.), even for a $681-\mathrm{kg}(1500-\mathrm{lb})$ payload. When the mast diameter exceeded about $1.40 \mathrm{~m}$ (55 in.), the static deflection dropped to $<0.0127 \mathrm{~m}(0.5 \mathrm{in}$.) and did not vary much with payload.

The total weight of the manipulator went up roughly with the square of the mast diameter because most of the total weight was in the mast. Since the minimum thickness of the mast was constrained to be $1 / 50$ of the diameter, the mast thickness went up with the mast diameter. The maximum stress on the mast decreased with the cube of the diameter. Since the stresses were very low for large mast diameters, the buckling constraint could be relaxed somewhat.

In addition to the above data, the first fifteen natural frequencies for a representative optimized design were determined. Typically, four frequencies of interest exist: two frequencies near the value indicated as the fundamental natural frequency and two at about twice the indicated value. The lowest mode of vibration tends to be motion of the arm in a horizontal plane with combined bending and torsional motion of the mast and bending of the arm. The second mode (very close to the first) is essentially in a vertical plane and involves in-phase bending of the arm and mast.

\subsubsection{Conclusions of the PNL Study}

The lowest natural frequency of the system was found to increase roughly linearly with the mast (or access port) diameter. Increasing the payload from 113 to $681 \mathrm{~kg}(250$ to $1500 \mathrm{lb}$ ) with a given mast diameter decreases the natural frequency by roughly $1 \mathrm{~Hz}$. The range of frequencies achievable (without considering joint compliance) varies from about $1 \mathrm{~Hz}$ for a $0.71-\mathrm{m}$ (28-in.) mast with a 681-kg (1500-lb) payload to about $5 \mathrm{~Hz}$ for a 1.63-m (64-in.) mast with a $114-\mathrm{kg}$ (250-lb) payload. For large mast diameters $[\sim 1.27 \mathrm{~m}(50 \mathrm{in})$.$] , the static deflections are very small [<0.0254 \mathrm{~m}(1 \mathrm{in})$.$] and$ the stresses on the mast and arm are very low, but the total weight is rather high [ $156000 \mathrm{~N}(35000 \mathrm{lbf})]$. These results indicate that a honeycomblike structure or a truss structure could be used to greatly reduce the total system weight without compromising strength. These structures could also increase passive damping. 
The buckling constraint requirement of $D / t \leq 50$ was a rule-of-thumb assumption. This constraint was likely too severe in some cases, particularly for larger access port diameters. For example, if the mast diameter is $1.27 \mathrm{~m}$ (50 in.), the maximum stress is very low, but this buckling constraint assumption requires that the mast thickness be $0.0254 \mathrm{~m}(1 \mathrm{in}$.$) , which seems$ excessively thick.

Apparently, a result of the optimization was to drive the system design such that is had two approximately equal fundamental frequencies. What the ramifications of closely spaced frequencies would be is not clear.. Some active vibration damping algorithms may not perform well with clumped natural frequencies.

\subsection{COMPARISON OF ORNL AND PNL STUDIES}

The primary differences between the ORNL and PNL studies were associated with the buckling constraints used and the optimization functions employed.

In the ORNL studies, the buckling constraint maintained the wall thickness at $\geq 0.00318 \mathrm{~m}(0.125 \mathrm{in}$.$) , while in the PNL studies, the ratio of diameter to$ thickness was maintained at $\leq 50$. This led to very different minimum thickness values, and thus, total manipulator weight. These different constraints were each determined by using rules-of-thumb, and should be examined more closely to determine actual requirements. Note that the total weight increases approximately linearly with the thickness, while stiffness increases primarily with diameter and only secondarily with thickness.

The ORNL optimization minimized weight, while the PNL optimization maximized the lowest natural frequency. The disadvantage of the ORNL approach is that it does not give a clear indication of the maximum stiffness achievable. Since the stiffness requirement is given as an input parameter, the resulting system dimensions and weight indicate only implicitly whether the given stiffness requirement is practically achievable. The disadvantage of the PNL approach is that it does not give a clear indication of the minimum weight design.

The two studies are quite complementary in this. Tendencies in achievable natural frequency, stiffness, and static deflection can be obtained from the PNL report to estimate manipulator performance for a given access port diameter, and a good estimate of the corresponding manipulator weight can be obtained from the ORNL reports. If further analysis of buckling constraints indicates that the minimum thickness must be increased, the manipulator weight can be readily approximated by multiplying the values in the ORNL studies by the increased wall thickness ratio for those conditions under which 
the minimum wall thickness was reached. (As another possibility, a trusslike or alternative structure could avoid the buckling problem. To avoid the buckling problem, the wall thickness would not necessarily have to be increased uniformly, which would result in a significant increase in the weight, so long as the stiffness and strength requirements are satisfied.)

Other differences between the ORNL and PNL studies include the use of circular cross-section links by PNL and hexagonal or square cross sections by ORNL and the use of continuous variables throughout by PNL and the use of discrete wall thicknesses by ORNL. These different approaches likely resulted in only minor differences in the results reported.

\subsection{CONCLUSIONS FROM THE MANIPULATOR PERFORMANCE STUDIES}

It may be assumed that the natural frequencies and static deflections are optimistic because compliance in the joints was not considered in any of the above studies. For industrial robots, one rule-of-thumb would be to assume that joint compliance and link deflections contribute equally. Tip deflections will increase with the square of the link lengths because of joint compliance, and with the cube of the link lengths because of link deflections. If it is assumed that joint compliance and link deflections contribute equally to the overall stiffness, then static deflections can be expected to be roughly double those obtained and natural frequencies can be expected to be about 0.7 times those obtained. The flexibility of the mast is dominant in determining the lowest natural frequency.

For small access port diameters, a uniform cross-section, shell-type structure will likely be required to meet stiffness and natural frequency requirements. For large-diameter access holes (greater than or equal to $\sim 1.14 \mathrm{~m}$ (45 in.), uniform cross-section designs tend to exhibit low stresses and minimal wall thicknesses determined by buckling constraints. Alternative honeycomb or trusslike structure designs should allow one to more appropriately satisfy buckling constraints. The result could be reduced weight for a given stiffness and natural frequency, increased stiffness and natural frequency for the same weight, or some optimal combination. 


\section{PRACTICAL STRUCTURAL LIMITATIONS}

The waste tank domes are constructed of concrete with steel reinforcing rods. Both circular and radial reinforcement rods were installed. Within a central area, only circular reinforcement rods were installed. It has been suggested that it would be desirable not to cut into the dome area containing radial reinforcement rods. However, the results of an assessment of the practical structural limitations associated with installing risers of various diameters have not been fully investigated at this time. An engineering report [Kaiser 1994] addresses the limitations of tank dome loading and riser diameter implications on modifications to the heel pit but does not address the question of the structural integrity of the tank dome. The report [Kaiser 1994] refers to a Westinghouse Hanford Company structural analysis study under way. Preliminary indications are that there is no significant limitation to the access hole diameter; diameters up to $3.10 \mathrm{~m}$ (122 in.) have been examined, and it is believed that even larger ones would be possible. 


\section{RISER INSTALLATION STATE-OF-THE-ART LIMITATIONS}

The engineering study referenced in Sect. 4 [Kaiser 1994] extrapolates a similar task performed by West Valley Nuclear Services of New York in 1986, which involved the installation of a $0.762-\mathrm{m}$ - (30-in.-) diameter penetration in the top of a nonradioactive concrete vault. It is suggssted that similar technology would allow the installation of $1.07-$ to $1.83-\mathrm{m}$ - (42- to 72 -in.-) diameter risers in the Hanford tanks. The report addresses the limitations of tank dome loading and riser diameter implications on modifications to the heel pit. It was estimated that the tank loading would be 44,500 to $22,200 \mathrm{~N}$ $(5,000$ to $10,000 \mathrm{lb}$.), which is significantly under the maximum allowable live load on the earth above the tank dome. It is noted in the report that to install a 1.83-m- (72-in.-) diameter riser, modifications to the heel pit would be required, which would not be required for the installation of a $1.52-\mathrm{m}$ (60-in.-) diameter riser. This difference is reflected in the estimated relative costs of installing 1.07-, 1.52-, and 1.83-m (42-, 60-, and 72-in.) risers. The step jump in cost occurs at about $1.57 \mathrm{~m}$ (62 in.). The estimated costs were $\$ 7.7 \mathrm{M}$ for a $1.07-\mathrm{m}(42-\mathrm{in}$.) riser, $\$ 8.0 \mathrm{M}$ for a $1.52-\mathrm{m}(60-\mathrm{in}$.) riser, and $\$ 9.9 \mathrm{M}$ for a 1.83-m (72-in.) riser.

The engineering study referenced above does not address the question of how large an access riser could be installed by using state-of-the-art technology; it only extrapolates that the installation of a 1.83- $\mathrm{m}$ (72-in.) diameter is feasible. One might conclude that even larger penetrations would be feasible as well. 


\section{RADIATION SAFETY IMPLICATIONS}

The radiation safety implications of various riser diameters was not addressed in the engineering study conducted by Kaiser [Kaiser, 1994]. Although the study includes a greenhouse for the containment of airborne contamination and appropriate heating, ventilating, and air conditioning equipment, the assumption was made that decontamination could be performed in order to avoid the use of remote tooling and/or shielding. A closed-circuit television system was included to allow monitoring by an operator located 3.05 to $6.10 \mathrm{~m}$ (10 to $20 \mathrm{ft}$ ) from the heel pit during the core drilling operation. It was recommended: "Further study of the radiation fields expected during core drilling should be performed. Additional shielding or remote operation will add significant cost to the project."

The needed information on the radiation safety implications and resulting cost implications of various riser diameters is not currently available. Obviously, the larger the access hole, the greater the aperture through which radiation will shine into the retrieval system base area. Additional shielding and contamination control measures would be required for larger holes.

The trade-off between increased radiation exposure due to use of the same access hole and increased hose management complexity was addressed in a separate engineering study [Evans 1994]. It was recommended that both the waste conveyance hose and the manipulator be installed through the same access hole, increasing the radiation exposure to the manipulator and reducing the effective access hole diameter. 


\section{OVERALL SYSTEM COST IMPLICATIONS}

In each element of this study are basic problems in determining the overall system cost implications of various access hole diameters. It seems obvious that the most desirable solution from a manipulator controls point of view is to make the manipulator as stiff as possible and have a natural frequency as high as possible, which implies a large access hole diameter. However, beyond some diameter in the 1.07- to $1.52-\mathrm{m}$ (42- to 60-in.) range, simple, uniform cross-section elements become less advantageous from a weight standpoint. The construction cost of larger manipulators will be greater, and the cost will be further increased if alternative structures are used. The basic issues are how much effort and money should be put into increasing the mechanical performance and reducing weight and how much would the cost be increased by selecting an alternative structure. Although significant effort has been placed on estimating the performance characteristics of manipulators of various diameters, a direct $t$. to the time required to perform the tank waste retrieval task has not been possible.

Although the final report is not available, no practical structural limitation to the size of access hole to be put in the tank is apparent. No apparent cost is associated with this, unless a requirement for special supports for the dome is identified, which might have an associated cost as a function of hole diameter. It is anticipated that this study would have an impact only if it is concluded that a hole size limitation is within the range being considered.

The state of the art in installing risers is based on work at West Valley, which was limited to a $0.762-\mathrm{m}-(30-i n$.) diameter riser. However, a study was conducted which indicates that risers in the range of 1.07 to $1.83 \mathrm{~m}$ (42 to 72 in.) in diameter are feasible. A cost jump occurs around $1.57 \mathrm{~m}$ (62 in.) because of the particular installation. Although this cost jump is on the order of $25 \%$, the increase in cost may be small compared to the overall cost of the waste retrieval project.

The radiation safety implications of various access hole diameters has not been adequately addressed at this point. However, one might assume that the larger the access hole, the greater the cost of providing radiation shielding. Significant questions regarding the need for remote tooling and operations were raised in the study performed by Kaiser Engineers Hanford Company, but these questions were not addressed in terms of access hole diameter. 


\section{CONCLUSIONS}

Clearly, that the overall cost of remediation will be dominated by the costs of the balance of plant and time required to perform the task rather than the cost of manipulator hardware or the cost of installing a riser. This cost will likely be associated primarily with design, construction, and setup, but it also will be impacted to some extent by the performance of the manipulator and other elements of the system.

The inost desirable solution from a manipulator controls point of view is to make the manipulator as stiff as possible and have as high as possible a natural frequency, which implies a large access hole diameter. Beyond some diameter, simpie, uniform cross-section elements become less advantageous from a weight standpoint. The construction cost of larger manipulators will be greater, and this cost will be increased further if alternative structures are used. However, until more extensive simulation (including practical operations tasks) and/or experimental testing can be performed to confirm anticipated performance improvements possible with advanced control algorithms, it seens prudent to recommend a large access hole diameter (the largest considered in the [Kaiser 1994] report), along with the riser installation and an alternative manipulator structure, which further increase the cost. A detailed study of alternative structures would be required in addition to radiation implications and riser installation implications to optimize the access riser diameter.

It should be noted that the parametric studies on manipulator performance were directed toward 3,790,000 l (1,000,000 gal) tanks; an approximately $15.2 \mathrm{~m}$ $(50 \mathrm{ft})$ long mast was assumed. If the design for the initial application is for a $2,840,000$ I ( $750,000 \mathrm{gal})$ tank, the mast length required will be reduced by approximately $2.3 \mathrm{~m}(7.5 \mathrm{ft})$, considering only the difference in tank liner heights. Therefore, the calculations should be somewhat conservative, recognizing the limitations of the specific conditions considered.

Additional shielding and contamination control measures would be required for larger holes.

A separate engineering study [Evans 1994] recommended that the waste conveyance hose be installed through the same access hole as the manipulator, increasing the radiation exposure to the manipulator and reducing the effective access hole diameter.

The recommendation to install the largest access riser considered in [Kaiser 1994] may be impacted by radiation safety implications or structural safety considerations which have not been formalized. 


\section{REFERENCES}

[Blevens 1979] R. D. Blevins, Formulas for Natural Frequency and Mode Shape Van Nostrand, New York (1979).

[Cook 1989] R. D. Cook, D. S. Malkus, and M. E. Plesha, Concepts and Applications of Finite Element Analysis, 3d Ed., Wiley, New York (1989).

[Evans 1994] M. S. Evans et al., Long Reach Manipulator End Effector Utility Lines and Conveyance System Routing, Pacific Northwest Laboratory, Draft Report, March 1994.

[Jansen 1992] J. F. Jansen et al., Long-Reach Manipulation for Waste Storage Tank Remediation - FY 1991 Report, ORNL/TM-11999, Oak Ridge National Laboratories, March 1992.

[Kaiser 1994] Kaiser Engineers Hanford Company, Tank 241-C-106 Penetration Enlargement, Sequencing, and Construction Estimate, Project 340, prepared for Westinghouse Hanford Company, WHC-SD-W340-ER-001, (Issue D), Preliminary Report, January 1994.

[Kwon 1993a] D. S. Kwon et al., Key Design Requirements for Long-Reach Manipulators, ORNL/TM-12251, Oak Ridge National Laboratories, September 1993.

[Kwon 1993b] D. S. Kwon, Parametric Design Studies of Long-Reach Manipulators, Proceedings of the ANS Fifth Topical Meeting on Robotics and Remote Handling, Apr. 26-29, 1993, pp. 265-73.

[Kwon 1993c] D. S. Kwon, Oak Ridge National Laboratories, internal communication, March 5, 1993.

[Stoughton 1994] B. Stoughton, Impact of Access Port Diameter on the Long Reach Manipulator Design, Pacific Northwest Laboratory Report PNL9439/UC-510, April 1994. 


\section{INTERNAL DISTRIBUTION}

1. G. A. Armstrong

2-22. S. M. Babcock

23. J. Baker

24. R. E. Barry

25. M. Beckerman

26. B. E. Bernacki

27. K. C. Bills

28. E. C. Bradley

29-49. B. L. Burks

50. J. B. Chesser

51. J. V. Draper

52. W. E. Dixon

53. R. L. Glassell

54. M. J. Haire

55-56. D. C. Haley

57-58. W. R. Hamel

59. S. N. Hammonds

60. J. H. Hannah

61-63. J. N. Herndon

64. D. H. Hwang

65. J. F. Jansen

66. J. P. Jones

67. S. M. Killough

68. H. E. Knee

69. R. L. Kress

70. C. T. Kring

71-76. D. S. Kwon

77. R. F. Lind

78. P. D. Lloyd

79. A. P. Malinauskas

80. R. C. Mann
81. M. W. Noakes

82. T. E. Noell

83. D. J. Nypaver

84. F. G. Pin

85. K. E. Plummer

86. P. M. Rathke

87. D. B. Reister

88. B. S. Richardson

89. J. C. Rowe

90. D. A. Schoenwald

91. S. L. Schrock

92. M. Simpson

93. J. O. Steigler

94. C. W. Summey

95. D. H. Thompson

96. H. Toy

97. M. A. Unseren

98. K. U. Vandergriff

99. J. D White

100. A. L. Wintenberg

101. H. R. Yook

102. ORNL Central Research Library

103. ORNL Document Reference Section

104-105. ORNL Laboratory Records

106. ORNL Laboratory Records RC

107. ORNL Patent Section

\section{EXTERNAL DISTRIBUTION}

108. Clinton Bastin, Manager, LMR Reprocessing Projects, Division of Fuels and Reprocessing, Office of Facilities, Fuel Cycle, and Test Programs, NE-471, Department of Energy, Washington, DC 20545.

109. D. W. Bennett, Pacific Northwest Laboratories, P.O. Box 999, Richland, WA 99352. 
110. R. Eschenbaum, Westinghouse Hanford Company, P.O. Box 1970, N1-21, Richland, WA 99352.

111-116. M. S. Evans, Pacific Northwest Laboratories, P.O. Box 999, Richland, WA 99352.

117-167. P. Gibbons, Westinghouse Hanford Company, 2355 Stevens Drive, Building MO-414, Richland, WA 99352

168. S. Gibson, EM 551, Trevion II, U.S. Department of Energy, Washington, D.C. 20585.

169. R. L. Gilchrist, Westinghouse Hanford Company, P.O. Box 1970, N121, Richland, WA 99352.

170. E. Goodman, Fusion and Nuclear Technology Branch, Energy Programs Division, Department of Energy, P.O. Box 2008, Oak Ridge, TN 37831-6269.

171. E. L. Grasz, Lawrence Livermore National Laboratory, P.O. Box 808, L-439, Livermore, CA 94550.

172. R. W. Harrigan, Sandia National Laboratories, P.O. Box 5800, Division 1414, Albuquerque, NM 87185

173. F. B. Hazen, Fernald Environmental Restoration Management Corporation, P.O. Box 398704, MS 81-2, Cincinnati, OH 45239-8704.

174. F. Heckendorn, Westinghouse Savannah River Company, Building 773-A, D-1145, Aiken, SC 29808.

175. D. Herman, Fernald Environmental Restoration Management Corporation, P.O. Box 398704, MS 81-2, Cincinnati, OH 45239-8704.

176. R. M. Hollen, Los Alamos National Laboratory, P.O. Box 1663, MS $\mathrm{J}-580$, Los Alamos, NM 87545

177. D. S. Horschel, Sandia National Laboratory, P.O. Box 5800, Division 1414, Department 1661, Albuquerque, NM 8718.

178. W. Jaquish, Westinghouse Hanford Company, LO-18, P.O. Box 1970, Richland, WA 99352.

179. L. McDaniel, Westinghouse Hanford Company, LO-18, P.O. Box 1970, Richland, WA 99352. 
180. E. Shen, Westinghouse Hanford Company, LO-18, P.O. Box 1970, Richland, WA 99352.

181. R. Singer, Westinghouse Savannah River Company, Building 773-A, D-1145, Aiken, SC 29808.

182-187. R. S. Stoughton, Pacific Northwest Laboratories, P.O. Box 999, Richland, WA 99352.

188. C. R. Ward, Westinghouse Savannah River Company, Building 773-A, D-1145, Aiken SC 29808

189. B. M. Wilding, Westinghouse Idaho Nuclear Company, P.O. Box 4000, Idaho Falls, ID 83403-5104

190. A. P. Williams, Westinghouse Hanford Company, LO-18, P.O. Box 1970, Richland, WA 99352.

191. L. W. Yarbrough, Department of Energy, 12800 Middlebrook Road, MS EM-55, Trevion II, Germantown, MD 20874

192. J. Yount, Westinghouse Hanford Company, LO-18, P.O. Box 1970, Richland, WA 99352

193. Office of Assistant Manager for Energy Research and Development, DOE Oak Ridge Field Office, P.O. Box 2008, Oak Ridge, TN 37831-6269

194-195. Office of Scientific and Technical Information, DOE Oak Kidge Field Office, P.O. Box 62, Oak Ridge, TN 37831. 

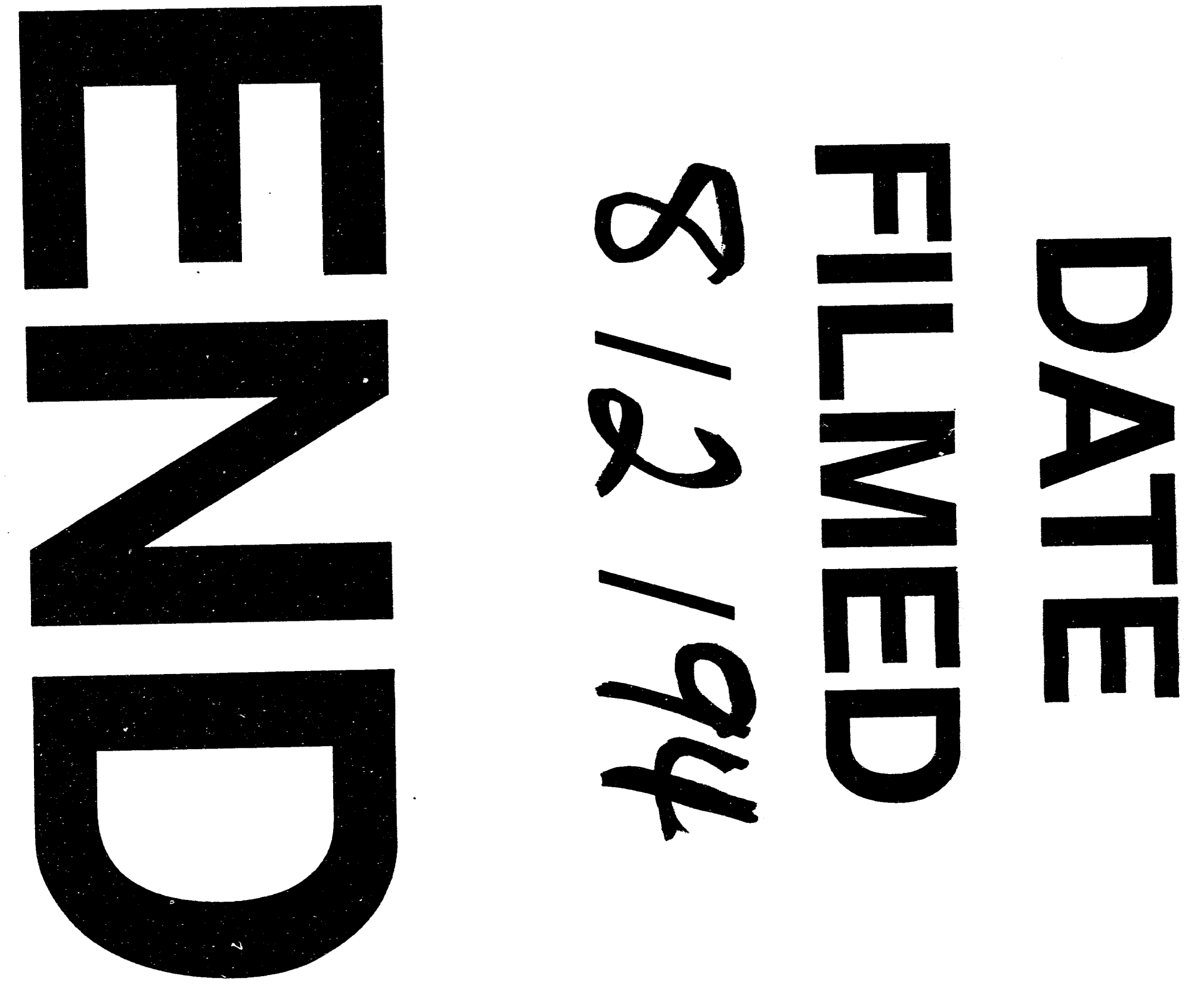
